\title{
Governança local no sistema descentralizado de saúde no Brasil
}

\author{
Sonia Fleury, ${ }^{1}$ Assis Luiz Mafort Ouverney, ${ }^{1,2}$ \\ Thais Soares Kronemberger ${ }^{1}$ e Felipe Barbosa Zani ${ }^{1}$
}

Como citar Fleury S, Ouverney ASM, Kronemberger TS, Zani FB. Governança local no sistema descentralizado de saúde no Brasil. Rev Panam Salud Publica. 2010;28(6):446-55.

RESUMO Objetivo. Analisar as mudanças decorrentes do processo de descentralização do Sistema Único de Saúde na governança do setor saúde no âmbito do poder local entre 1996 e 2006.

Métodos. Um questionário foi aplicado aos gestores municipais de saúde de todo o Brasil em 1996 e novamente em 2006. Foram coletadas informações sobre as características de inovação da gestão em três dimensões: social, gerencial e assistencial. O presente artigo analisa resultados referentes à dimensão social da gestão (relação entre a gestão municipal e os diferentes atores da sociedade) a partir de quatro atributos: elaboração do orçamento (qual o grau de influência de atores variados), estabelecimento de prioridades, prestação de contas e fluxo de informações para a sociedade.

Resultados. Aumentou a influência dos secretários e dos conselhos municipais de saúde na elaboração do orçamento, em detrimento da influência dos políticos locais. Na definição de prioridades em saúde, reduziu-se a solicitação dos políticos locais e a demanda espontânea e fortaleceram-se o parecer do corpo técnico e as propostas dos conselhos e das conferências de saúde. Observa-se a institucionalização da prática de prestação de contas em virtude da diversificação do conjunto de atores a que se direciona (especialmente câmara de vereadores e conselho de saúde) e dos mecanismos utilizados, embora continue prevalecendo o uso de balancete periódico (que implica em conhecimento técnico para interpretação dos resultados). Por fim, as informações oferecidas à população ainda se referem acima de tudo às ações e campanhas de saúde e ao funcionamento de serviços, embora tenha crescido a divulgação de informações inovadoras à sociedade. Esse padrão se observa em todas as regiões e portes populacionais, com tendências mais progressivas na região Sul.

Conclusões. A relação entre estado e sociedade modificou-se em direção a um padrão mais democrático de governança local, embora tenham sido mantidas práticas governamentais concentradoras de poder na tomada de decisão. O processo de descentralização ainda encontra obstáculos importantes para a concretização de um modelo de maior participação, controle social, responsabilização e interação entre Estado e sociedade.

Palavras-chave Sistema Único de Saúde; descentralização; governo local; política de saúde; Brasil.

O Sistema Único de Saúde (SUS), desenhado como parte do processo de de-

1 Fundação Getúlio Vargas (FGV), Escola Brasileira de Administração Pública (EBAPE), Programa de Estudos da Esfera Pública (PEEP), Rio de Janeiro (RJ), Brasil. Correspondência: Sonia Fleury, sonia.fleury@fgv.br

2 Fundação Oswaldo Cruz (FIOCRUZ), Escola Nacional de Saúde Pública Sérgio Arouca (ENSP), Escola de Governo em Saúde, Rio de Janeiro (RJ), Brasil. mocratização cujo marco é a Constituição de 1988, orienta-se pelas diretrizes da universalidade e integralidade da cobertura, do reconhecimento dos direitos sociais de cidadania, da afirmação do dever do Estado, da subordinação das práticas privadas à regulação tendo em vista a relevância pública das ações e serviços sociais, de um arranjo organizacional descentralizado caracterizado pelo federalismo cooperativo e de uma perspectiva participativa de cogestão Estado/ sociedade $(1,2)$.

Entretanto, o período de implantação e desenvolvimento do SUS coincidiu, nos anos 1990, com a emergência de uma nova agenda de reformas, que implicou em importantes transformações na estrutura 
econômica e política do País, envolvendo as relações Estado/mercado/sociedade e as relações intergovernamentais (3-5). $\mathrm{Na}$ esfera econômica, predominou a agenda de estabilização monetária mediante emprego de regimes de metas de inflação, câmbio flutuante, apreciação da taxa de juros, endividamento interno e superávits fiscais em detrimento de uma política de desenvolvimento de longo prazo. No plano federativo, as reformas impulsionaram a reconcentração de poder na União, mediante redução da autonomia das esferas subnacionais, com concentração de recursos financeiros no âmbito central e fortalecimento da capacidade de coordenação federativa do gestor federal por diversos instrumentos, como indução financeira e regulação legal, programas de endividamento dos estados e municípios, Lei de Responsabilidade Fiscal e emendas de vinculação de recursos, de privatização dos bancos estaduais e de ampliação assimétrica da carga tributária, entre outros (6-9). No âmbito interno, a reforma administrativa privilegiou a formação de núcleos estratégicos, transferindo ao mercado atividades produtivas e compartilhando funções com a sociedade civil, o que resultou em redução de estrutura, composição de quadros e alcance de sua capacidade planejadora.

Essa agenda de reformas proporcionou um cenário desfavorável à construção de políticas universais, na medida em que reduziu a capacidade do país para formular e implementar políticas mais democráticas e inclusivas de desenvolvimento. Isso porque ampliou a preponderância e a valorização ideológica do mercado na provisão de bens e serviços sociais, reduziu o papel da sociedade civil nos processos de formulação e planejamento governamental, diminuiu a base de financiamento das políticas sociais, enfraqueceu a ação do Estado na direção dos processos socioeconômicos, reduziu a disponibilidade de recursos na área social, intensificou a verticalização das relações federativas com poucos estímulos ao compartilhamento de funções e produziu incentivos à individualização da proteção, entre outros. Mesmo em meio a esse cenário, o processo de construção do SUS avançou, sendo conduzido a partir da União em direção à descentralização municipal com base na pactuação de marcos normativos temporários, associados a instrumentos de indução financeira e monitoramento gerencial, com o objetivo de formar competências e estru- turas descentralizadas de gestão e provisão de serviços de saúde $(10,11)$.

Desde o início da década de 1990, a adesão paulatina de estados e municípios a condições negociadas de forma tripartite (municípios, estados e união), em nível nacional, permitiu a construção de bases institucionais federativas consistentes $(12,13)$, com a transferência progressiva de responsabilidades sanitárias a estados e municípios. A expansão da oferta de serviços (14) ocorreu juntamente com a introdução de mudanças nos modelos e práticas de cuidado (15). Consolidaram-se, no período, o estabelecimento de processos estáveis de formulação, implementação e monitoramento (16) e a ampliação da base de financiamento tripartite $(17,18)$.

No modelo descentralizado, os municípios passaram a gerenciar a grande maioria das unidades públicas de provisão de serviços de saúde, além de assumir também a responsabilidade formal pela contratação, monitoramento e avaliação (gestão) de amplo conjunto de unidades privadas. Segundo informações disponíveis para o ano de 2010 no Cadastro Nacional de Estabelecimentos de Saúde (CNES), administrado pelo Ministério da Saúde, de um total de 221056 estabelecimentos de saúde, 59663 (27\%) eram municipais, o que corresponde a aproximadamente $95,6 \%$ da oferta pública de estabelecimentos de saúde que, incluindo as unidades estaduais e federais, totalizavam 62437 unidades em 2010. Da mesma forma, uma expressiva parcela da oferta privada de unidades contratadas junto ao mercado também está sob gestão municipal. De 25471 estabelecimentos contratados ou conveniados que prestam serviços de diversas naturezas (ambulatorial, internação, apoio diagnóstico terapêutico, urgência, vigilância e farmácia), cerca de 15170 , ou seja, 59,6\%, estão sob gestão da esfera municipal (19). Em termos de produção de serviços de saúde, mesmo considerando os estabelecimentos apenas por sua propriedade, a participação da oferta municipal é extremamente significativa, sendo majoritária na atenção básica e na média complexidade.

A análise da produção do SUS em 2009 mostra que, de um total de aproximadamente 3,246 bilhões de procedimentos ambulatoriais, a esfera local foi diretamente responsável pela produção de $96,4 \%$ na atenção básica e $43,4 \%$ na média complexidade. No total da oferta de ser- viços ambulatoriais, a esfera local realiza $61,3 \%$ dos procedimentos (19). Na oferta de serviços hospitalares, de um montante de 11,5 milhões de internações ofertadas pelo SUS, aproximadamente 55,32\% (6,37 milhões) foram realizadas sob gestão municipal. Nesse conjunto, os municípios foram responsáveis por $61,9 \%$ das internações de psiquiatria, $60,3 \%$ das internações de obstetrícia, 60,1\% das internações de clínica médica, 59,7\% das internações de pneumonologia e $54,2 \%$ das internações de pediatria.

Informações relativas ao financiamento do setor saúde para o ano de 2006 demonstram que, de um total de $\mathrm{R} \$ 84,033$ bilhões (correntes), os municípios foram responsáveis por $\mathrm{R} \$ 23,484$ bilhões, considerando apenas os gastos com recursos próprios, o que representa $27,9 \%$ dos gastos públicos com saúde no Brasil. Entretanto, se considerarmos o gasto total executado pela esfera local em saúde (gastos com recursos próprios + transferências setoriais), o valor chega a $\mathrm{R} \$ 40,682$ bilhões. Isso significa que os municípios geriram quase metade $(48,4 \%)$ de todos os recursos disponíveis ao SUS em 2006 (20).

Além do elevado domínio de recursos e das amplas competências de gestão, os municípios ainda possuem significativa influência na definição das políticas regionais e nacionais de saúde, por meio das entidades corporativas que possuem representação nas instâncias federativas de governança do SUS: as comissões intergestores bipartite (entre estado e municípios) e a comissão intergestores tripartite (entre União, estados e municípios). Nessas instâncias são negociadas prioridades e recursos, bem como definidas estratégias de descentralização e transferência de recursos e os instrumentos de planejamento e gestão compartilhada. Além da participação constante nas decisões regionais e nacionais, a esfera local ainda atua na formação da política de médio prazo por meio da convocação periódica das conferências de saúde, nas quais ocorre um processo de debate de temas selecionados como estratégicos para a política de saúde.

Diversos desafios, antigos e novos, compõem a fronteira de consolidação institucional do SUS, exigindo não só o aperfeiçoamento das competências técnicas e gerenciais, mas também o enfrentamento de dilemas políticos estruturantes. Esses desafios envolvem a definição das responsabilidades federativas (11, 21), a relação com outras políticas sociais 
TABELA 1. Distribuição por região e porte populacional dos questionários sobre governança local do setor saúde respondidos por secretários de saúde, Brasil, 1996 e 2006

\begin{tabular}{|c|c|c|c|c|c|c|c|c|c|c|}
\hline \multirow[b]{2}{*}{ Ano } & \multicolumn{5}{|c|}{ Regiãoa $^{a}$} & \multicolumn{5}{|c|}{ Habitantes } \\
\hline & $\mathrm{N}$ & $\mathrm{NE}$ & $\mathrm{CO}$ & SE & S & $<5000$ & $\begin{array}{l}5000 a \\
20000\end{array}$ & $\begin{array}{c}20000 \mathrm{a} \\
50000\end{array}$ & $\begin{array}{l}50000 \mathrm{a} \\
200000\end{array}$ & $>200000$ \\
\hline \multicolumn{11}{|l|}{1996} \\
\hline Número de municípios & 398 & 1558 & 426 & 1533 & 1058 & 1067 & 2544 & 903 & 376 & 83 \\
\hline Número de respondentes & 78 & 238 & 114 & 563 & 429 & 271 & 661 & 300 & 153 & 37 \\
\hline$\%$ de resposta & 19,6 & 15,3 & 26,8 & 36,7 & 40,5 & 25,4 & 26,0 & 33,2 & 40,7 & 44,6 \\
\hline \multicolumn{11}{|l|}{2006} \\
\hline$\%$ resposta & 9,6 & 14,0 & 19,4 & 25,2 & 23,5 & 16,5 & 17,9 & 20,3 & 28,4 & 62,1 \\
\hline
\end{tabular}

${ }^{\mathrm{a}} \mathrm{CO}=$ Centro-Oeste; $\mathrm{N}=$ Norte; $\mathrm{NE}=$ Nordeste $\mathrm{S}=\mathrm{Sul} ; \mathrm{SE}=$ Sudeste.

(22), o acesso e a utilização de serviços especializados (23), a ampliação da equidade tanto no acesso quanto na qualidade dos serviços (24), a regulação contratual e gerencial sobre o setor complementar (25), o fortalecimento do controle social $(26,27)$ e a construção de bases consistentes de planejamento regional (28), entre outros.

Sejam quais forem as estratégias a serem adotadas, a atual configuração institucional do SUS, se mantida, torna a esfera local um lócus privilegiado de resolução desses desafios e dilemas. Torna-se, pois, fundamental para o sucesso dessas estratégias a construção de bases sólidas de governança local, capazes de fornecer suporte técnico, gerencial e político às políticas de saúde.

O objetivo deste artigo é analisar os impactos do processo de descentralização na configuração da governança no âmbito do poder local, tendo como foco a democratização da relação Estadosociedade no período compreendido entre 1996 e 2006 no Brasil.

\section{MATERIAIS E MÉTODOS}

Os dados analisados neste estudo foram coletados por meio de um questionário enviado por correio aos secretários municipais de saúde em âmbito nacional, contando com o apoio dos Conselhos de Secretários Municipais de Saúde na divulgação da pesquisa. Os questionários foram aplicados em 1996 e posteriormente em 2006. Em ambas as ocasiões, foram distribuídos a todos os municípios do País. Em 1996, o retorno foi de $28 \%$, variando de 15,3 a $40,5 \%$ entre as regiões. Em 2006, o retorno total foi 19,5\%, com variação regional de 9,6 a 25,2\%. Enquanto em 1996 optou-se por considerar a amostra de questionários recebidos como autorrepresentativa, em
2006 foi feito um trabalho estatístico de ponderação por expansão da amostra para torná-la representativa. Essa ponderação foi feita em função do volume menor de questionários respondidos, o que motivou o apoio de análises estatísticas de representatividade durante a coleta de informações. A partir dessas análise, foram enviados novos conjuntos de questionários para regiões e portes específicos. A tabela 1 discrimina o total de municípios e o número de questionários respondidos em cada ano, por região e porte populacional.

O questionário, elaborado especialmente para o presente estudo, foi formado por dois blocos de questões. O primeiro bloco referiu-se ao perfil do gestor e o segundo às características de inovação da gestão em três dimensões: social, gerencial e assistencial. Este artigo abrange apenas os resultados da dimensão social, que compreende questões referentes à relação estabelecida entre a gestão municipal e os diferentes setores da sociedade. Não foram abordadas outras questões relativas à governança local, como a forma de provisão de serviços, a regulação do sistema ou seu financiamento, que foram desenvolvidas nas demais dimensões do estudo. $\mathrm{O}$ questionário aplicado em 1996 e 2006 seguiu o mesmo desenho, ainda que algumas atualizações tenham sido realizadas, com acréscimo de perguntas no questionário de 2006. O objetivo dessa atualização foi captar as tendências mais recentes da descentralização do SUS.

Para análise das características da relação Estado-sociedade subjacentes à governança local foram selecionados, a partir da análise da literatura e da consulta a especialistas do setor saúde convidados, quatro atributos da dimensão social, com variáveis correspondentes, como mostra a tabela 2: elaboração do orçamento anual, definição de prioridades, prestação de contas e fluxos de informação para a sociedade. As respostas foram reunidas em uma base de dados eletrônica e tabuladas por grande região geográfica e por porte populacional.

\section{RESULTADOS}

\section{Influência de atores na elaboração do orçamento}

Em 2006, os prefeitos (82,0\%) e os secretários de saúde $(49,5 \%)$ foram os atores que mais exerceram influência na elaboração do orçamento municipal (tabela 3). Por outro lado, o Conselho Municipal de Saúde, instância de participação e deliberação da política de saúde pela sociedade civil, foi considerado por $28,3 \%$ dos secretários como um ator de alta influência na definição dos recursos municipais. $\mathrm{Na}$ análise por região, o conselho municipal de saúde destacou-se como mais influente no Sul (35,5\%), sendo menos expressivo no Sudeste $(20,6 \%)$ e no Norte (20,7\%). Em relação ao porte populacional, a maioria dos prefeitos e dos secretários de saúde exerceu alta influência na elaboração do orçamento em municípios acima de 200000 habitantes (76,6\% e $66,9 \%$, respectivamente). O judiciário não foi considerado um ator expressivo na definição dos recursos municipais, nem os consultores ou empresas de consultoria externa, embora a influência desses últimos tenha crescido, principalmente em municípios de 50000 a 200000 habitantes (1,3 para 10,9\%).

Na década de 1996 a 2006, aumentou a influência do secretário de saúde e do conselho municipal de saúde na elaboração do orçamento municipal. Nesse mesmo período, diminuiu de forma expressiva o percentual de localidades onde os políticos locais exerciam alta influência na ela- 
TABELA 2. Características de inovação da gestão local do setor saúde na dimensão social, Brasil, 1996 e 2006

\begin{tabular}{|c|c|c|c|c|}
\hline Atributos & Variável & Pergunta do questionário & Opções de resposta & Tendências esperadas de inovação \\
\hline $\begin{array}{l}\text { Elaboração do } \\
\text { orçamento }\end{array}$ & $\begin{array}{l}\text { Influência dos } \\
\text { atores na } \\
\text { elaboração }\end{array}$ & $\begin{array}{l}\text { Grau de influência dos } \\
\text { atores na elaboração do } \\
\text { orçamento municipal }\end{array}$ & $\begin{array}{l}\text { Atores: prefeito, secretário de saúde, outros } \\
\text { secretários, conselho municipal de saúde, poder } \\
\text { judiciário, associações da sociedade civil, políticos } \\
\text { locais, consultores ou empresas de consultoria } \\
\text { externa, mais dois itens de livre escolha do gestor }\end{array}$ & $\begin{array}{l}\text { - Ampliação do escopo de atores com } \\
\text { influência significativa na elaboração } \\
\text { - Incorporação de interesses plurais } \\
\text { - Redução do peso de atores tradicionais } \\
\text { (prefeito, políticos locais) e expansão } \\
\text { da influência de novos atores }\end{array}$ \\
\hline $\begin{array}{l}\text { Estabelecimento } \\
\text { de prioridades }\end{array}$ & $\begin{array}{l}\text { Importância dos } \\
\text { itens (itens } \\
\text { relevantes) }\end{array}$ & $\begin{array}{l}\text { Grau de importância do } \\
\text { item no estabelecimento } \\
\text { de prioridades em } \\
\text { saúde }\end{array}$ & $\begin{array}{l}\text { Itens considerados: parecer do corpo técnico, } \\
\text { propostas de conselhos ou conferências de } \\
\text { saúde, solicitação de políticos locais, sugestões } \\
\text { de outras esferas (comissão bipartite, estado ou } \\
\text { União), pressão dos meios de comunicação de } \\
\text { massa, incentivos financeiros do Ministério da } \\
\text { Saúde, decisões do Judiciário, pressão de } \\
\text { associações da sociedade civil, mais dois itens de } \\
\text { livre escolha do gestor }\end{array}$ & $\begin{array}{l}\text { - Redução da influência de formas } \\
\text { incrementais e fragmentadas de } \\
\text { estabelecimento de prioridades } \\
\text { - Ampliação das formas organizadas e } \\
\text { tecnicamente fundamentadas de } \\
\text { incorporação de interesses }\end{array}$ \\
\hline \multirow[t]{2}{*}{$\begin{array}{l}\text { Prestação de } \\
\text { contas }\end{array}$} & $\begin{array}{l}\text { Interlocutores/ } \\
\text { instrumentos e } \\
\text { mecanismos }\end{array}$ & $\begin{array}{l}\text { A quem a secretaria de } \\
\text { saúde presta contas }\end{array}$ & $\begin{array}{l}\text { Atores: associações da sociedade civil, câmara de } \\
\text { vereadores, conselho de saúde, prefeito, } \\
\text { comissões intergestores, outras secretarias, outro } \\
\text { órgão municipal (livre escolha), não presta contas, } \\
\text { mais um item de livre escolha do gestor }\end{array}$ & $\begin{array}{l}\text { - Institucionalização da prática de } \\
\text { prestação de contas } \\
\text { - Ampliação do escopo de atores e } \\
\text { instâncias aos quais os gestores } \\
\text { prestam contas }\end{array}$ \\
\hline & & $\begin{array}{c}\text { Mecanismos utilizados } \\
\text { pela secretaria para a } \\
\text { prestação de contas }\end{array}$ & $\begin{array}{l}\text { Mecanismos: balancetes periódicos, audiência } \\
\text { pública, meios de comunicação (rádio, TV, } \\
\text { jornais), Internet, locais públicos, nenhum, mais } \\
\text { um item de livre escolha do gestor }\end{array}$ & $\begin{array}{l}\text { - Diversificação e ampliação dos } \\
\text { mecanismos de prestação de contas }\end{array}$ \\
\hline $\begin{array}{l}\text { Fluxo de } \\
\text { informações }\end{array}$ & $\begin{array}{l}\text { Tipo de informação } \\
\text { oferecida }\end{array}$ & $\begin{array}{l}\text { Informações regularmente } \\
\text { oferecidas à população } \\
\text { através dos meios de } \\
\text { comunicação } \\
\text { disponíveis }\end{array}$ & $\begin{array}{l}\text { Informações: divulgação de ações e campanhas, } \\
\text { funcionamento de serviços, informações } \\
\text { específicas para os conselhos ou semelhante, } \\
\text { resultados da gestão, nenhuma, mais um item de } \\
\text { livre escolha do gestor }\end{array}$ & $\begin{array}{l}\text { - Institucionalização da prática de } \\
\text { divulgação de informações à } \\
\text { população } \\
\text { - Diversificação do tipo de informação } \\
\text { oferecida à população }\end{array}$ \\
\hline
\end{tabular}

TABELA 3. Influência dos atores envolvidos na elaboração do orçamento conforme questionário aplicado a secretários municipais de saúde, Brasil, 1996 e $2006^{a, b}$

\begin{tabular}{|c|c|c|c|c|c|c|c|c|c|c|c|c|c|c|c|c|c|c|c|c|c|c|}
\hline \multirow[b]{3}{*}{ Atores } & & & \multicolumn{10}{|c|}{ Região (\%) } & \multicolumn{10}{|c|}{ Habitantes (\%) } \\
\hline & \multicolumn{2}{|c|}{ Total } & \multicolumn{2}{|c|}{ Norte } & \multicolumn{2}{|c|}{ Nordeste } & \multicolumn{2}{|c|}{$\begin{array}{c}\text { Centro- } \\
\text { Oeste } \\
\end{array}$} & \multicolumn{2}{|c|}{ Sudeste } & \multicolumn{2}{|c|}{ Sul } & \multicolumn{2}{|c|}{$<5000$} & \multicolumn{2}{|c|}{$\begin{array}{l}5000 \mathrm{a} \\
20000\end{array}$} & \multicolumn{2}{|c|}{$\begin{array}{c}20000 \mathrm{a} \\
50000\end{array}$} & \multicolumn{2}{|c|}{$\begin{array}{c}50000 \mathrm{a} \\
200000\end{array}$} & \multicolumn{2}{|c|}{$>200000$} \\
\hline & Q1 & Q2 & Q1 & Q2 & Q1 & Q2 & Q1 & Q2 & Q1 & Q2 & Q1 & Q2 & Q1 & Q2 & Q1 & Q2 & Q1 & Q2 & Q1 & Q2 & Q1 & Q2 \\
\hline $\begin{array}{l}\text { Prefeito } \\
\text { Secretário }\end{array}$ & 76,7 & 82,0 & 69,3 & 81,7 & 75,2 & 82,7 & 76,1 & 77,4 & 79,3 & 83,9 & 75,8 & 80,1 & 79,0 & 81,6 & 75,4 & 81,6 & 74,7 & 85,9 & 80,4 & 77,9 & 86,5 & 76,6 \\
\hline $\begin{array}{l}\text { de saúde } \\
\text { Outros }\end{array}$ & 24,8 & 49,5 & 25,6 & 51,0 & 18,9 & 46,6 & 25,7 & 51,4 & 23,4 & 44,5 & 29,3 & 59,7 & 27,7 & 54,1 & 22,4 & 43,1 & 19,7 & 57,2 & 36,5 & 56,6 & 37,8 & 66,9 \\
\hline secretários & 15,2 & 21,5 & 15,4 & 21,4 & 10,5 & 20,7 & 16,8 & 17,0 & 13,9 & 20,0 & 19,1 & 26,5 & 19,2 & 25,6 & 12,3 & 18,6 & 12,3 & 19,4 & 22,9 & 32,8 & 29,7 & 26,6 \\
\hline $\mathrm{CMS}^{\mathrm{C}}$ & 15,3 & 28,3 & 25,6 & 20,7 & 14,7 & 30,7 & 12,4 & 36,0 & 14,6 & 20,6 & 15,6 & 35,5 & 19,2 & 37,8 & 15,1 & 25,6 & 11,7 & 27,8 & 15,0 & 25,5 & 21,6 & 19,5 \\
\hline $\begin{array}{l}\text { Judiciáriod } \\
\text { Associações }\end{array}$ & NA & 12,3 & NA & 12,0 & NA & 9,3 & NA & 9,2 & NA & 11,9 & NA & 18,6 & NA & 18,6 & NA & 13,1 & NA & 7,0 & NA & 5,5 & NA & 5,5 \\
\hline $\begin{array}{c}\text { civis }^{d} \\
\text { Políticos }\end{array}$ & NA & 10,4 & NA & 7,8 & NA & 10,2 & NA & 8,2 & NA & 8,8 & NA & 14,8 & NA & 13,1 & NA & 8,6 & NA & 11,3 & NA & 11,4 & NA & 15,1 \\
\hline locais & 19,0 & 10,4 & 23,1 & 7,3 & 21,4 & 8,9 & 26,5 & 12,5 & 19,4 & 11,4 & 14,4 & 11,6 & 19,9 & 15,5 & 19,2 & 8,6 & 22,0 & 10,4 & 9,8 & 8,6 & 21,6 & 11,1 \\
\hline Consultores & 5,9 & 9,6 & 9,0 & 11,4 & 9,2 & 12,0 & 10,6 & 11,4 & 5,0 & 9,5 & 3,5 & 4,5 & 7,7 & 8,2 & 6,1 & 10,7 & 6,3 & 8,2 & 1,3 & 10,9 & 5,4 & 2,4 \\
\hline
\end{tabular}

a Q1 = questionário aplicado em 1996. Q2 = questionário aplicado em 2006.

b NA: não se aplica - itens inexistentes no questionário aplicado em 1996.

c $\mathrm{CMS}=$ conselho municipal de saúde.

d Itens acrescentados ao questionário de 2006.

boração do orçamento nas regiões Norte, Nordeste e Centro-Oeste, bem como nos municípios com 5000 até 20000 habitantes, 20000 até 50000 habitantes e nos municípios acima de 200000 habitantes.

\section{Definição de prioridades em saúde}

Em 2006, na percepção dos secretários de saúde, o parecer do corpo técnico $(62,8 \%)$, as propostas de conselhos ou conferências de saúde (58,3\%) e os incentivos financeiros do Ministério da Saúde (50,3\%) constituíram os itens mais relevantes para o estabelecimento de prioridades em saúde nos municípios (tabela 4). 
TABELA 4. Importância de cada item considerado no estabelecimento de prioridades em saúde conforme questionário aplicado a secretários municipais de saúde, Brasil, 1996 e 2006

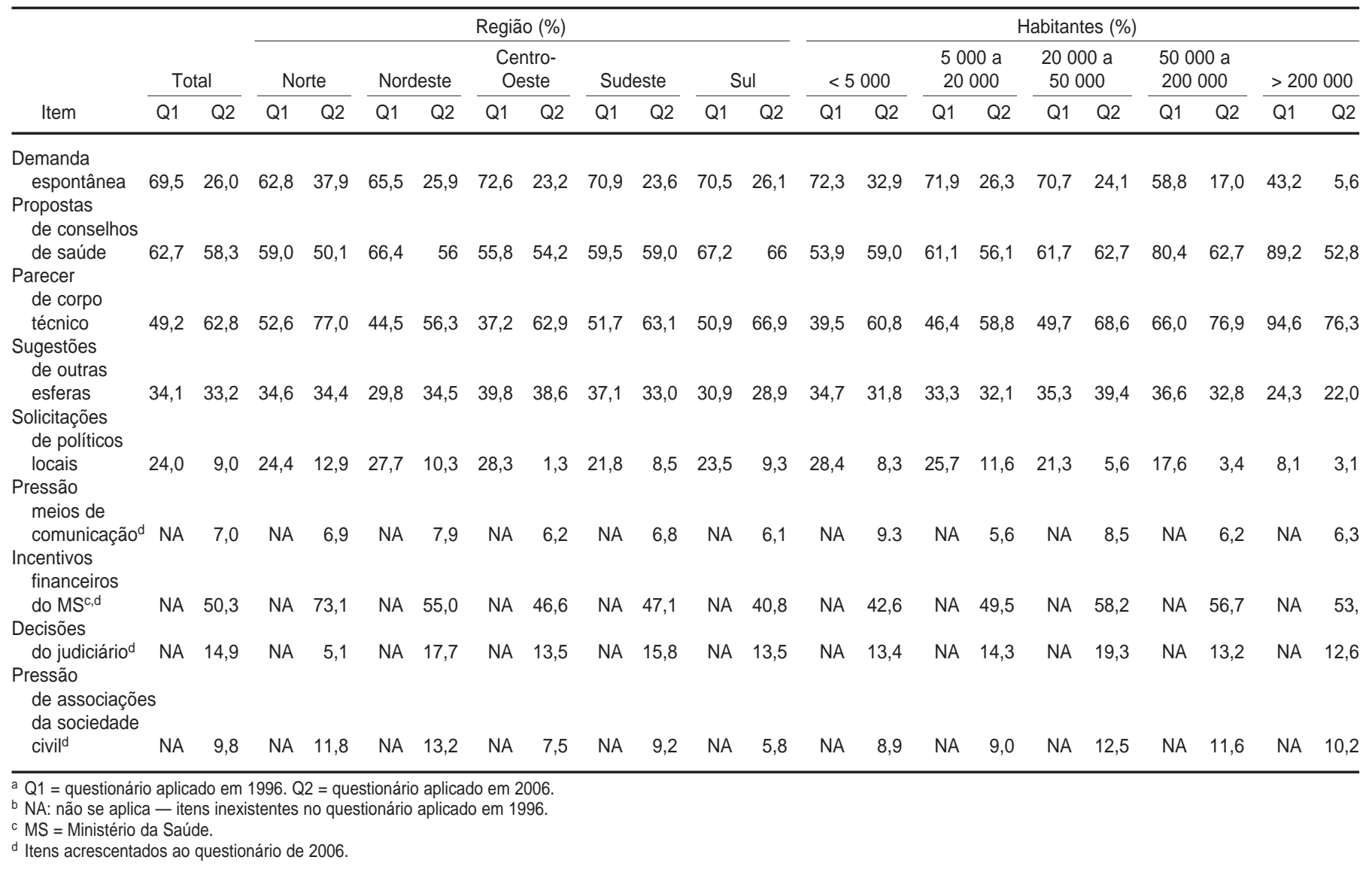

Na década de 1996 a 2006 houve mudança nos critérios adotados para alocação de prioridades, com redução da demanda espontânea $(69,5$ para $26,0 \%)$ e das solicitações de políticos locais $(24,0$ para $9,0 \%$, cuja importância diminuiu em todas as regiões, principalmente no Centro-Oeste. Essa tendência declinante foi observada em todas as faixas populacionais, sendo que o atendimento a solicitações de políticos locais caiu de forma expressiva nos municípios de até 5000 habitantes, o que indica um fortalecimento técnico dos menores municípios. Por outro lado, durante a década estudada, o parecer do corpo técnico ganhou força na definição de prioridades de saúde nos municípios, principalmente nas regiões Norte e Centro-Oeste. Em relação às propostas de conselhos ou conferências de saúde, nas regiões Nordeste e Norte, ou seja, nas regiões menos desenvolvidas, reduziu-se substancialmente a importância desses critérios no estabelecimento de prioridades em saúde. Quanto ao porte populacional, verificamos que, em todas as faixas po- pulacionais, exceto nos municípios acima de 200000 habitantes, o parecer do corpo técnico aumentou significativamente sua importância no estabelecimento de prioridades em saúde, principalmente nos municípios de até 5000 habitantes (tabela 4).

\section{Prestação de contas das secretarias de saúde}

Em 2006, a maioria das secretarias de saúde prestava contas ao conselho municipal de saúde $(92,7 \%)$, ao prefeito $(78,8 \%)$ e à câmara de vereadores $(74,7 \%)$ (tabela 5). Somente 0,9\% declararam que não prestavam contas. Na década, houve um aumento no percentual de secretarias de saúde que prestam contas a todos os atores, sobretudo às câmara de vereadores e aos conselho de saúde.

Assim como em 1996, em 2006 a Região Sul apresentou os maiores percentuais de secretarias que prestavam contas. As secretarias de saúde dos municípios com mais de 200000 habitantes foram as que mais prestaram contas.

\section{Mecanismos de prestação de contas}

Como mostra a tabela 6, o mecanismo mais utilizado para a prestação de contas das secretarias de saúde foi o balancete periódico $(76,9 \%$ em 2006 e 75,0\% em 1996), modalidade que, além de obrigatória, é essencialmente técnica, o que pode representar um obstáculo ao avanço da transparência se não for combinada com outras formas de prestação de contas, dada a dificuldade no entendimento das informações ofertadas (tabela 6). Por outro lado, 45,3\% das secretarias realizavam audiência pública para prestação de contas, forma considerada mais democrática e que possibilita a ampliação do debate na esfera pública. Vale destacar o aumento da utilização dos meios de comunicação de massa (rádio, TV, jornais) no período de 1996 a 2006.

As secretarias de saúde da Região Sul utilizavam fortemente a audiência pública para prestação de contas. Além disso, foram as que mais utilizaram os demais instrumentos alternativos ao balancete periódico, quais sejam, locais pú- 
TABELA 5. Instituições às quais prestam contas as secretarias municipais de saúde conforme questionário aplicado a secretários municipais de saúde, Brasil, 1996 e 2006,

\begin{tabular}{|c|c|c|c|c|c|c|c|c|c|c|c|c|c|c|c|c|c|c|c|c|c|c|}
\hline \multirow[b]{3}{*}{ Instituições } & & & \multicolumn{10}{|c|}{ Região (\%) } & \multicolumn{10}{|c|}{ Habitantes (\%) } \\
\hline & \multicolumn{2}{|c|}{ Total } & \multicolumn{2}{|c|}{ Norte } & \multicolumn{2}{|c|}{ Nordeste } & \multicolumn{2}{|c|}{$\begin{array}{l}\text { Centro- } \\
\text { Oeste }\end{array}$} & \multicolumn{2}{|c|}{ Sudeste } & \multicolumn{2}{|c|}{ Sul } & \multicolumn{2}{|c|}{$<5000$} & \multicolumn{2}{|c|}{$\begin{array}{l}5000 a \\
20000\end{array}$} & \multicolumn{2}{|c|}{$\begin{array}{c}20000 \mathrm{a} \\
50000\end{array}$} & \multicolumn{2}{|c|}{$\begin{array}{l}50000 \mathrm{a} \\
200000\end{array}$} & \multicolumn{2}{|c|}{$>200000$} \\
\hline & Q1 & Q2 & Q1 & Q2 & Q1 & Q2 & Q1 & Q2 & Q1 & Q2 & Q1 & Q2 & Q1 & Q2 & Q1 & Q2 & Q1 & Q2 & Q1 & Q2 & Q1 & $\bar{Q} 2$ \\
\hline \multicolumn{23}{|l|}{ Conselho } \\
\hline Prefeito & $\begin{array}{l}04,0 \\
65,5\end{array}$ & 78,8 & 55,1 & 78,8 & $\begin{array}{l}50,5 \\
57,1\end{array}$ & 74,7 & $\begin{array}{l}2,2 \\
67,3\end{array}$ & $\begin{array}{l}9<, 0 \\
76,2\end{array}$ & $\begin{array}{l}67,0 \\
67,3\end{array}$ & $\begin{array}{l}8,1 \\
80,7\end{array}$ & $\begin{array}{l}09,0 \\
69,3\end{array}$ & 83,1 & 70,8 & $\begin{array}{l}1,1 \\
78,5\end{array}$ & $\begin{array}{l}01,9 \\
62,5\end{array}$ & $\begin{array}{l}97,0 \\
77,3\end{array}$ & $\begin{array}{l}60,3 \\
67,3\end{array}$ & $\begin{array}{l}4,2 \\
81,2\end{array}$ & 66,0 & $\begin{array}{l}1,4 \\
81,5\end{array}$ & $\begin{array}{l}94,9 \\
64,9\end{array}$ & $\begin{array}{l}90,1 \\
82,8\end{array}$ \\
\hline $\begin{array}{l}\text { civis } \\
\text { Outras }\end{array}$ & 2,3 & 23,9 & 1,3 & 25,5 & 2,1 & 16,2 & 1,8 & 23,6 & 2,0 & 25,1 & 3,0 & 33,6 & 2,6 & 26,3 & 1,4 & 22,3 & 2,7 & 23,7 & 4,6 & 26,2 & 2,7 & 32,0 \\
\hline $\begin{array}{l}\text { secretarias }^{c} \\
\text { Comissões }\end{array}$ & NA & 15,4 & NA & 20,5 & NA & 11,6 & NA & 13,4 & NA & 12,9 & NA & 23,5 & NA & 20,1 & NA & 13,3 & NA & 12,9 & NA & 20,2 & NA & 25 , \\
\hline $\begin{array}{l}\text { intergestores } \\
\text { Outro órgão }\end{array}$ & NA & 10,9 & NA & 10,5 & NA & 7,2 & NA & 14,6 & NA & 15 & NA & 9,5 & NA & 10,1 & NA & 8,9 & NA & 13,5 & NA & 16,4 & NA & 24,0 \\
\hline municipal & 7,0 & 6,5 & 11,5 & 7,2 & 7,6 & 6,7 & 8,0 & 2,4 & 6,7 & 6,6 & 5,8 & 7,5 & 3,3 & 5,7 & 7,1 & 6,2 & 4,7 & 8,6 & 11,8 & 5,7 & 29,7 & 5,9 \\
\hline respondeu & 0,7 & 0,9 & 1,3 & $-^{d}$ & 0,4 & 0,9 & 3,5 & 0,2 & 0,4 & 0,9 & 0,5 & 1,3 & 1,1 & 0,9 & 0,9 & 0,6 & 0,3 & 0,4 & $-^{d}$ & 2,9 & $-^{d}$ & 3,3 \\
\hline
\end{tabular}

a Q1 = questionário aplicado em 1996. Q2 = questionário aplicado em 2006.

b NA: não se aplica — itens inexistentes no questionário aplicado em 1996.

c Itens acrescentados ao questionário de 2006.

d Magnitude menor do que 0,1 .

blicos, meios de comunicação e internet. Já as secretarias do Nordeste pouco utilizavam os meios de comunicação e a audiência pública, e as secretarias do Norte, por sua vez, raramente utilizam os meios de comunicação. Porém, houve uma elevação no percentual de secretarias que passaram a utilizar meios de comunicação de massa no Sul, no Sudeste e no Centro-Oeste. $\mathrm{Na}$ análise por porte populacional, verificou-se que, em geral, quanto maior o porte do município, maior a utilização de audiência pública e Internet para prestação de contas. Em relação a 1996, houve redução de balancetes periódicos nos municípios de 50000 a 200000 habitantes e com mais de 200000 habitantes. A utilização dos meios de comunicação só diminuiu nos municípios com mais de 200000 habitantes.

\section{Informações oferecidas à população}

Para além da prestação de contas, assim como em 1996, as informações mais oferecidas à população em 2006 foram referentes às ações e campanhas $(95,7 \%)$ e ao funcionamento dos serviços $(72,9 \%)$ (tabela 7). Contudo, a década de 1996 a 2006 foi marcada por considerável aumento no percentual de secretarias que divulgavam informações inovadoras à sociedade, principalmente referentes aos resultados da gestão (18,6\% para 37,9\%).
Enquanto a Região Norte apresentou os menores percentuais de secretarias que divulgavam regularmente informações sobre o funcionamento dos serviços e os resultados da gestão, além de informações específicas para os conselhos ou semelhantes $(32,6 \%)$, a Região Sul apresentou os maiores percentuais para a divulgação dessas informações.

\section{DISCUSSÃO}

Diferentes estudos têm mostrado que as relações entre governança, accountability e responsividade nas novas democracias dependem, fundamentalmente, do desenho institucional a elas conferido e de sua adequação às condições da sociedade (29). Se a responsividade diz respeito a fazer as coisas certas do modo certo, pode ser apreendida através das dimensões gerenciais e assistenciais consideradas em nosso estudo. Por outro lado, a responsabilidade pelo bom governo deve ser compreendida como apenas um dos componentes da governança, já que as relações mútuas entre governo e sociedade constituem-se na dimensão social da governança. Portanto, consideramos que a governança, para além de um atributo do Estado, é também uma característica relacional que envolve a sociedade a ser governada (30), devendo, pois, ser apreendida dentro dessa perspectiva relacional, envolvendo tanto os modos de exercício da autoridade como também os processos de inserção dos interesses sociais na agenda governamental.

No presente estudo, observamos que, na década de 1996 a 2006, aumentou o percentual de gestores que atribuíam alta influência ao secretário de saúde e ao conselho municipal de saúde na elaboração do orçamento municipal. Esses dados refletem a institucionalização do modelo de governança local como parte do processo de descentralização, como também sugerem a inversão da posição de influência dos atores políticos locais e dos atores políticos setoriais (secretário de saúde e conselhos). Com exceção do Sudeste, onde não houve variação significativa, e do Norte, em que o conselho municipal de saúde diminuiu a sua influência (25,6 para 20,7\%), observamos que nas demais regiões geográficas do País aumentou a influência do conselho municipal de saúde e do secretário de saúde na elaboração do orçamento.

De forma geral, podemos afirmar que, durante a década de 1996 a 2006, houve maior participação e diversificação de atores políticos com influência na elaboração do orçamento, indicando maior permeabilidade à inserção de interesses plurais, representados pelos conselhos, e também o fortalecimento do poder técnico político setorial, representado pelo próprio secre- 
TABELA 6. Mecanismos utilizados para a prestação de contas pelas secretarias municipais de saúde conforme questionário aplicado a secretários municipais de saúde, Brasil, 1996 e 2006 a,b

\begin{tabular}{|c|c|c|c|c|c|c|c|c|c|c|c|c|c|c|c|c|c|c|c|c|c|c|}
\hline \multirow[b]{3}{*}{ Mecanismo } & & & \multicolumn{10}{|c|}{ Região (\%) } & \multicolumn{10}{|c|}{ Habitantes (\%) } \\
\hline & \multicolumn{2}{|c|}{ Total } & \multicolumn{2}{|c|}{ Norte } & \multicolumn{2}{|c|}{ Nordeste } & \multicolumn{2}{|c|}{$\begin{array}{l}\text { Centro- } \\
\text { Oeste }\end{array}$} & \multicolumn{2}{|c|}{ Sudeste } & \multicolumn{2}{|c|}{ Sul } & \multicolumn{2}{|c|}{$<5000$} & \multicolumn{2}{|c|}{$\begin{array}{l}5000 \mathrm{a} \\
20000\end{array}$} & \multicolumn{2}{|c|}{$\begin{array}{c}20000 \mathrm{a} \\
50000\end{array}$} & \multicolumn{2}{|c|}{$\begin{array}{l}50000 a \\
200000\end{array}$} & \multicolumn{2}{|c|}{$>200000$} \\
\hline & Q1 & Q2 & Q1 & Q2 & Q1 & Q2 & Q1 & Q2 & Q1 & Q2 & Q1 & Q2 & Q1 & Q2 & Q1 & Q2 & Q1 & Q2 & Q1 & Q2 & Q1 & Q2 \\
\hline Balancetes & & & & & & & & & & & & & & & & & & & & & & \\
\hline $\begin{array}{l}\text { periódicos } \\
\text { Audiência }\end{array}$ & 75,0 & 76,9 & 73,1 & 68,8 & 69,3 & 78,2 & 68,1 & 88,7 & 77,1 & 76,6 & 77,7 & 73,8 & 66,4 & 80,3 & 71,9 & 73,5 & 80,3 & 81,4 & 90,2 & 77,8 & 89,2 & 81,4 \\
\hline $\begin{array}{l}\text { públicac } \\
\text { Locais }\end{array}$ & NA & 45,3 & NA & 40,6 & NA & 24,2 & NA & 46,2 & NA & 49,1 & NA & 73,5 & NA & 43,8 & NA & 41,5 & NA & 46,8 & NA & 61 & NA & 7 \\
\hline $\begin{array}{l}\text { públicos } \\
\text { Meios de }\end{array}$ & NA & 23,7 & NA & 27,6 & NA & 20,0 & NA & 22,5 & NA & 20,6 & NA & 32,9 & NA & 27,8 & NA & 22,9 & NA & 21,7 & NA & 25,6 & NA & 17,6 \\
\hline comunicação & 9,8 & 19,6 & 5,1 & 6,2 & 8,8 & 10,8 & 3,5 & 24,6 & 8,0 & 23,2 & 15,1 & 30,9 & 7,4 & 17,6 & 9,2 & 18,8 & 10,3 & 21,3 & 13,7 & 28,0 & 16,2 & 13,8 \\
\hline Internet ${ }^{\mathrm{C}}$ & NA & 11,4 & NA & 6,4 & NA & 11,0 & NA & 8,5 & NA & 11,9 & NA & 14,6 & NA & 11,1 & NA & 9,2 & NA & 11,9 & NA & 22,1 & NA & 23,6 \\
\hline Outros & 13,2 & 10,6 & 9,0 & 12,6 & 13,4 & 14,6 & 9,7 & 11,3 & 13 & 9,4 & 14,9 & 5,3 & 12,9 & 12,5 & 12,7 & 9,2 & 11,3 & 13,1 & 15,7 & 9,5 & 27 & 9,3 \\
\hline Nenhum & 10,8 & 2,1 & 16,7 & $-\mathrm{d}$ & 13,9 & 3,6 & 19,5 & 3,8 & 10,5 & 2,1 & 6,3 & $-d$ & 15,9 & 1,5 & 12,0 & 2,5 & 9,3 & 1,7 & 2,6 & 2,6 & $-d$ & $-d$ \\
\hline Não respondeu & 2,6 & 1,8 & 3,8 & 1,2 & 2,9 & 2,6 & 2,7 & 0,2 & 2,1 & 1,8 & 2,8 & 1,3 & 3,3 & 0,9 & 3,2 & 1,8 & 1,7 & 1,4 & 0,7 & 4,1 & 2,7 & 3,3 \\
\hline
\end{tabular}

a Q1 = questionário aplicado em 1996. Q2 = questionário aplicado em 2006.

b NA: não se aplica - itens inexistentes no questionário aplicado em 1996.

c Itens acrescentados ao questionário de 2006

d Magnitude menor do que 0,1 .

TABELA 7. Tipo de informação oferecida à população pelas secretarias municipais de saúde conforme questionário aplicado a secretários municipais de saúde, Brasil, 1996 e $2006^{a, b}$

\begin{tabular}{|c|c|c|c|c|c|c|c|c|c|c|c|c|c|c|c|c|c|c|c|c|c|c|}
\hline \multirow[b]{3}{*}{ Informação } & & & \multicolumn{10}{|c|}{ Região (\%) } & \multicolumn{10}{|c|}{ Habitantes (\%) } \\
\hline & \multicolumn{2}{|c|}{ Total } & \multicolumn{2}{|c|}{ Norte } & \multicolumn{2}{|c|}{ Nordeste } & \multicolumn{2}{|c|}{$\begin{array}{l}\text { Centro- } \\
\text { Oeste }\end{array}$} & \multicolumn{2}{|c|}{ Sudeste } & \multicolumn{2}{|c|}{ Sul } & \multicolumn{2}{|c|}{$<5000$} & \multicolumn{2}{|c|}{$\begin{array}{l}5000 a \\
20000\end{array}$} & \multicolumn{2}{|c|}{$\begin{array}{c}20000 \mathrm{a} \\
50000\end{array}$} & \multicolumn{2}{|c|}{$\begin{array}{l}50000 a \\
200000\end{array}$} & \multicolumn{2}{|c|}{$>200000$} \\
\hline & Q1 & Q2 & Q1 & Q2 & Q1 & Q2 & Q1 & Q2 & Q1 & Q2 & Q1 & Q2 & Q1 & Q2 & Q1 & Q2 & Q1 & Q2 & Q1 & Q2 & Q1 & Q2 \\
\hline $\begin{array}{l}\text { Ações e } \\
\text { campanhas }\end{array}$ & 85,0 & 95,7 & 76,9 & 95,1 & 83,6 & 95,9 & 80,5 & 94,2 & 83,3 & 95,1 & 90,5 & 97,2 & 80,8 & 95,8 & 81,7 & 96,1 & 89,7 & 94,0 & 94,1 & 99,4 & 97,3 & 87,3 \\
\hline Funcionamento & & & & & & & & & & & & & & & & & & & & & & \\
\hline serviços & 58,4 & 72,9 & 39,7 & 61,2 & 55,9 & 77,1 & 52,2 & 71,4 & 57,0 & 71,1 & 66,7 & 74,0 & 54,2 & 76,4 & 55,7 & 69,3 & 59,7 & 73,0 & 70,6 & 84,9 & 78,4 & 78,9 \\
\hline da gestão & 18,6 & 37,9 & 11,5 & 29,7 & 16,0 & 36,5 & 15,0 & 31,8 & 17,9 & 37,2 & 23,3 & 46,4 & 13,7 & 30,1 & 16,5 & 35,4 & 19,0 & 43,6 & 28,8 & 55,7 & 48,6 & 54,9 \\
\hline Outros & 3,7 & 4,6 & 5,1 & 4 & 2,5 & 4,4 & 4,4 & 3,1 & 4,1 & 4,5 & 3,3 & 5,6 & 2,6 & 5,4 & 3,6 & 4,8 & 2,3 & 2,9 & 5,9 & 5,2 & 13,5 & 1,9 \\
\hline Nenhuma & 3,1 & 0,6 & 6,4 & $-^{d}$ & 2,1 & 0,5 & 4,4 & $-^{d}$ & 4,6 & 1,2 & 0,7 & 0,4 & 4,8 & 0,5 & 3,6 & 1,0 & 1,7 & $-^{d}$ & 0,7 & $-^{d}$ & 2,7 & $-\mathrm{c}$ \\
\hline Não respondeu & 0,7 & 1,3 & 1,3 & 1,9 & 0,8 & 1,1 & 1,8 & 3,6 & 0,2 & 0,9 & 0,9 & 1,3 & 0,7 & 1,6 & 1,2 & 1,1 & $-^{d}$ & 2,0 & $-^{d}$ & 0,6 & $-^{d}$ & 0,8 \\
\hline
\end{tabular}

a Q1 = questionário aplicado em 1996. Q2 = questionário aplicado em 2006.

b NA: não se aplica - itens inexistentes no questionário aplicado em 1996.

c CMS = conselho municipal de saúde.

d Magnitude menor do que 0,1 .

tário e por consultores. O crescimento da influência do prefeito mostra que o fortalecimento da autoridade local não é um fenômeno específico do setor saúde, devendo ser explicado no contexto geral da descentralização e consolidação do poder local ocorridas no País.

A responsabilidade da autoridade local no desenvolvimento e gestão da política de saúde envolve atribuições legais relativas a gerência e gestão das unidades de serviços de saúde, além do pagamento a prestadores privados. A autoridade legal é responsável por construir a relação direta com o cidadão na prestação de serviços, sendo majoritariamente responsável pela organização e gestão de unidades, especialmente na atenção primária. Responsabiliza-se ademais pela cele- bração de contratos e convênios, pela compra de insumos e equipamentos, pela contratação de profissionais e pela implantação de programas nacionais em diversas políticas setoriais. Estão sob responsabilidade local a construção de sistemas de vigilância, avaliação, controle e monitoramento dos serviços e a gestão dos recursos financeiros próprios e recebidos por transferências intergovernamentais, entre outros $(31,32)$.

O desenho da descentralização no Brasil impulsionou um duplo movimento de democratização, representado pela transferência de competências e recursos à esfera local e pelo compartilhamento decisório com a sociedade civil organizada (33). Como resultado, o conjunto de atores formalmente habilitados a influenciar a formulação de estratégias, a elaboração de políticas e programas e a gestão de ações e serviços de saúde foi significativamente ampliado, assim como foram institucionalizadas instâncias e processos de participação e negociação. A concretização da participação da sociedade no processo de cogestão da política de saúde se deu com a institucionalização da participação de membros do governo e da sociedade nos conselhos de saúde, em âmbito local, regional e nacional. O modelo local de governança da saúde pode ser entendido como o conjunto de atores sociais, instituições e instâncias que compõem os processos decisórios, de responsabilização e prestação de contas subjacentes à formulação e execução da política municipal de saúde. Isso representa 
não só gerenciar a maior parte dos recursos do setor, como também possuir espaço privilegiado no processo de construção da política de saúde em âmbito regional e nacional.

O presente estudo baseou-se na hipótese de que o processo de descentralização de recursos e atribuições legais para a gestão municipal contribui tanto para a democratização do sistema de poder quanto para o aperfeiçoamento da capacidade de gestão da esfera local. Os dados apresentados mostraram uma tendência de consolidação do modelo de governança local em saúde com o processo de descentralização, no qual o parecer do corpo técnico é valorizado pelos secretários no estabelecimento das prioridades em saúde nos municípios, o que evidencia uma gestão de política de saúde voltada para a eficiência e a eficácia dessa política pública.

O parecer do corpo técnico, que em tese concorre com as propostas dos conselhos ou conferências de saúde, com a demanda espontânea e principalmente com as solicitações de políticos locais, destaca-se como um critério emergente. Isso sugere um aumento na base técnica da política local de saúde, ou na mediação técnica das relações políticas. Outro critério relevante, ao analisarmos o processo de descentralização do SUS e seu impacto na gestão local, é a importância dos recursos do Ministério da Saúde no estabelecimento das prioridades em saúde, o que indica uma indução das políticas municipais por parte do governo federal, compatível com o desenho da descentralização, mas que poderia, por outro lado, em virtude do emprego de transferências financeiras vinculadas a políticas específicas, levar à fragmentação do planejamento dos municípios e redução de sua autonomia de gestão.

De modo geral, a prática de prestação de contas é cada vez mais institucionalizada na relação das secretarias de saúde com as instâncias de participação e de representação da cidadania, especialmente para o conselho municipal de saúde e para a câmara de vereadores. Mesmo outros atores que não são destinatários legais da prestação de contas do poder executivo estão sendo considerados como relevantes para a prestação de contas, embora os percentuais ainda sejam reduzidos se comparados com prefeito, câmara de vereadores e conselho de saúde. Cabe destacar que a ênfase da prestação de contas nos pequenos muni- cípios se deslocou do prefeito para o conselho municipal de saúde, enquanto que os municípios de grande porte já prestavam contas ao conselho municipal, de maneira generalizada, desde 1996. De todas as maneiras, confirma-se a consolidação do novo modelo de governança local, mesmo que em diferentes etapas em relação aos instrumentos utilizados.

Quanto ao fornecimento de informações em saúde, ainda que a diferenciação regional na cultura política e desenvolvimento institucional seja uma manifestação geral da polarização e desigualdades regionais no País, chama atenção a existência de tendências opostas entre as regiões: na Região Sul observou-se um aumento relevante nos percentuais de secretarias que divulgavam informações específicas para os conselhos ou semelhantes e que informavam os resultados da gestão; enquanto isso, o Norte apresentou diminuição no percentual de secretarias que divulgavam informação específica para os conselhos ou semelhantes. Essa região também apresentou o maior aumento no percentual de secretarias que divulgavam à população informações tradicionais, relativas às ações e campanhas e ao funcionamento de serviços. A análise por porte populacional revelou que em 2006, assim como em 1996, quanto maior o porte do município, maior o percentual de secretarias que informavam à população os resultados de sua gestão.

As relações Estado-sociedade que fundamentam a governança local em saúde compreendem um conjunto de estruturas, desenvolvidas a partir da institucionalização do SUS, que viabilizam a existência de uma arena pública para a qual são canalizados os interesses dos diferentes atores envolvidos. No interior dessas estruturas, os interesses sociais devem ser reconhecidos e confrontados, permitindo sua circulação e a construção de alianças entre atores sociais e também a intermediação de interesses entre esses atores e a burocracia estatal. Por ser um espaço público, esse processo de inclusão e de participação permitiria a democratização da política de saúde. Esse desenho está fundamentado na concepção de que o Estado deve conter mecanismos institucionais de controle e de incorporação de interesses plurais que possam viabilizar sua inserção e evitar, ao mesmo tempo, a captura do Estado por grupos particulares.

A existência de canais de inserção de demandas e interesses em uma arena pública busca transformar o processo decisório em termos do aumento de pluralidade, transparência e incidência da sociedade na formulação e execução das políticas, além de funcionar como um processo pedagógico para a sociedade civil organizada. A construção de processos consistentes de governança para esse complexo local envolve estratégias adequadas para a intermediação das relações entre os gestores e os diversos atores presentes na arena sanitária dos municípios. Assim, a atitude e as competências de gestão necessárias para a produção de resultados coletivos no campo sanitário local, a partir de interesses possivelmente divergentes, envolvem a construção de processos de articulação política e de mediação de conflitos, o que exige que os gestores atuem permanentemente na construção de agendas de compartilhamento de percepções e ajustes de interesses.

Esse processo envolve ainda o desenvolvimento de relações de complementaridade entre burocracia e a sociedade civil organizada, visando a construir suporte político para a elaboração e a implementação de políticas e programas. Da mesma forma, tais relações permitem e impulsionam a ação organizada no sentido de ampliar a capacidade de monitoramento e fiscalização de metas e resultados, o que contribui significativamente para ampliar tanto o grau de accountability da gestão quanto a eficiência da ação estatal.

Embora seja evidente a institucionalização da participação da sociedade organizada via conferências e conselhos de saúde na definição de prioridades, estratégias e metas da política de saúde nas três esferas da federação, permanece ainda por se consolidar a capacidade efetiva de influência e controle social no processo decisório e de implementação das políticas de saúde (34). Diversos fatores influem nesse processo, tais como a disponibilidade de recursos para a operação dos conselhos, a cultura política de cada município, o nível de instrução da população, as relações do executivo com o legislativo, a ação de lideranças, a origem social dos membros dos próprios conselhos, entre outros.

Pesquisas com conselheiros apontaram o predomínio do caráter apenas consultivo dessas instâncias, em detrimento de seu papel decisório, enfatizando que, em algumas situações, os canais de participação operam somente na legitimação de decisões previamente definidas pelo executivo $(35,36)$. Ou, ainda, assinalaram o 
predomínio dos interesses de corporações profissionais sobre os de usuários e demais atores que participam das instâncias colegiadas (37). No entanto, a maioria desses estudos trata das relações entre gestor e conselheiros apenas no âmbito do conselho nacional ou em estudos de casos locais. Uma caracterização nacional da governança local como no presente estudo, a ser mais explorada em estudos futuros, é fundamental para o sucesso das estratégias de aperfeiçoamento institucional do SUS.

\section{CONSIDERAÇÕES FINAIS}

A análise geral dos resultados para os quatro atributos da governança local elaboração e execução do orçamento, estabelecimento de prioridades, prestação de contas e fluxo de informações - permite afirmar que houve modificações importantes na relação Estado-sociedade, em direção a um padrão mais democrático de exercício do poder local. Observou-se a ampliação do escopo de atores envolvidos na definição de prioridades e na elaboração do orçamento e a institucionalização dos canais de participação e controle social. Além disso, cada vez mais a sociedade recebe informações diversas, incluindo a prestação de contas de gestão, a partir de diferentes mecanismos e meios. Essa tendência é comum às diversas regiões do País e distintos portes populacionais. Portanto, confirmaram-se nossas hipóteses de que o novo desenho institucional descentralizado possibilitou o surgimento de formas híbridas de gestão, em especial o conselho de saúde, que geraram um novo padrão de governança, caracterizado pela maior distribuição e equalização dos recursos de poder, participação de novos atores e aumento do controle social e da prestação de contas. Em outras palavras, esse novo padrão de governança local é marcado pelo aumento da accountability.

Entretanto, dentro do conjunto de atributos selecionados, cabe diferenciar entre aqueles relativos ao processo decisório da gestão (definição de prioridades para a política de saúde e influência na elaboração do orçamento municipal) e os que dizem respeito ao controle social estrito (interlocutores e instrumentos da prestação de contas e tipo de informações oferecidas). Era esperado que o processo de descentralização conduzisse à democratização a partir de uma relação sinérgica entre esses dois processos: quanto mais acesso à informação sobre a gestão governamental tiver a sociedade, maior a sua capacidade de interferir nos rumos da política setorial.

Porém, os resultados apresentados demonstram tendências diferenciadas. Em relação aos atributos referentes ao controle social, houve institucionalização da prática de prestação de contas, acompanhada da diversificação e ampliação dos mecanismos utilizados. O mesmo pode ser verificado em relação ao tipo de informações oferecidas à sociedade.

Já no que se refere ao processo decisório, apesar dos avanços no controle social, e apesar de a definição de prioridades ser cada vez mais fundamentada em critérios técnicos e demandas institucionalizadas vindas do conselho municipal de saúde, verifica-se, na elaboração do orçamento, um espaço limitado para a inserção de outros atores além do prefeito e do secretário municipal de saúde. Portanto, verificamos déficits ainda acentuados de responsividade na governança local.

Deve-se considerar a tradição cultural brasileira de escassa participação e o pouco tempo de implantação do SUS para explicar essas tendências divergentes, com um aumento da prestação de contas que não encontra correspondência na responsabilização das autoridades governamentais. O próprio fato de a elaboração da lei orçamentária ser uma prerrogativa do poder executivo é uma expressão dessa cultura política.

Ainda que os resultados analisados neste artigo tomem como base apenas a percepção dos gestores, o que é limitado para comprovar as mudanças, sendo necessário o cotejamento com as percepções de usuários e sociedade civil organizada, fica claro que as limitações no novo padrão de governança não apenas existem, como foram explicitas pelo gestor local. O processo de descentralização, apesar de produzir impactos positivos na democratização da governança local em saúde, ainda encontra obstáculos importantes para a concretização de expectativas referentes à transformação da participação em um processo efetivo de alocação de recursos. Essa disjuntiva entre participação e controle social e poder de alocação efetivo poderá gerar tensões no desenho e dinâmica da governança local em saúde. Em outras palavras, torna-se necessário que o novo padrão de governança seja capaz de avançar simultaneamente nos seus dois componentes, accountability e responsividade.

\section{REFERÊNCIAS}

1. Fleury S. Cidadania e desenvolvimento humano no Brasil. Em: Calderón F, org. Ciudadanía y desarrollo humano. Buenos Aires: Siglo XXI; 2007. Pp. 243-74.

2. Fleury S, Mafort AL. Gestão de redes: a estratégia de regionalização da política de saúde. Rio de Janeiro: FGV; 2007.

3. Abrúcio FL, Loureiro MR, orgs. O Estado numa era de reformas: os anos FHC. Brasília: ENAP; 2002.

4. Costa NR. Política social e ajuste macroeconômico. Cad Saude Publica. 2002;18(supl.): 13-21.

5. Noronha JC, Soares LT. A política de saúde no Brasil nos anos 90. Cienc Saude Coletiva. 2001;6(2):445-50.

6. Melo MA. O sucesso inesperado das reformas de segunda geração: federalismo, reformas constitucionais e política social. Dados. 2005; $48(4) 845-89$.
7. Couto CG, Arantes RB. Constituição ou políticas públicas? Uma avaliação dos anos FHC. Em: Abrúcio FL, Loureiro MR, orgs. O Estado numa era de reformas: os anos FHC. Brasília: ENAP; 2002. Pp. 75-120.

8. Arretche M. Federalismo e relações intergovernamentais no Brasil: a reforma dos programas sociais. Dados. 2002;43:431-58.

9. Abrúcio FL. A coordenação federativa no Brasil: a experiência do período FHC e os desafios do governo Lula. Rev Sociol Polit. 2005; 24:41-67.

10. Levicovitz E, Lima LD, Machado CV. Política de Saúde nos anos 90: relações intergovernamentais e o papel das normas operacionais básicas. Cienc Saude Coletiva. 2001;6(2):269-91.

11. Mafort ALM. Os desafios da gestão em rede no SUS: situando a regionalização no centro da estratégia da política de saúde. Divulg Saude Debate. 2008;42:12-22.
12. Lima LD. Federalismo, relações fiscais e financiamento do Sistema Único de Saúde: a distribuição de receitas vinculadas à saúde nos orçamentos municipais e estaduais. Rio de Janeiro: Museu da República, 2007.

13. Ribeiro JM. Conselhos de saúde, comissões intergestores e grupos de interesses no Sistema Único de Saúde (SUS). Cad Saude Publica. 1997;13(1):81-92.

14. Costa NR, Pinto LF. Avaliação de programa de atenção à saúde: incentivo à oferta de atenção ambulatorial e a experiência da descentralização no Brasil. Cien Saude Coletiva. 2002;7(4):907-923.

15. Costa GD, Cotta RMM, Ferreira MLSM, Reis JR, Franceschini SCC. Saúde da família: desafios no processo de reorientação do modelo assistencial. Rev Bras Enferm. 2009;62(1):113-8.

16. Machado CV. Direito universal, política nacional: o papel do Ministério da Saúde na po- 
lítica de saúde brasileira de 1990 a 2002. Rio de Janeiro: Museu da República, 2007.

17. Marques RM, Mendes A. A política de incentivos do Ministério da Saúde para a atenção básica: uma ameaça à autonomia dos gestores municipais e ao princípio da integralidade? Cad Saude Publica. 2002;18(supl.):163-71.

18. Ugá MA, Piola SF, Porto SM, Vianna SM. Descentralização e alocação de recursos no âmbito do Sistema Único de Saúde (SUS). Cienc Saude Coletiva. 2003;8(2):417-37.

19. Brasil, Ministério da Saúde. Secretaria Executiva, Banco de Dados do Sistema Único de Saúde (DATASUS). Informações em saúde. Disponível em: http://tabnet.datasus.gov. $\mathrm{br} / \mathrm{cgi} /$ deftohtm.exe?sia/cnv/qauf.def. Acessado em abril de 2009.

20. Brasil, Ministério da Saúde, Secretaria Executiva. Sistema de Informações Sobre Orçamentos Públicos em Saúde. Acompanhamento. Disponível em: siops.datasus.gov.br/acompfin.php? esc $=6$. Acessado em 10 de abril de 2009.

21. Santos L, Andrade LOM. O espaço da gestão inovadora e dos consensos interfederativos. Aspectos jurídicos, administrativos e financeiros. Campinas: Instituto de Direito Sanitário Aplicado; 2007.

22. Fleury S. A seguridade social e os dilemas da inclusão social. Rev Adm Pública. 2005;39:449-69.

23. Oliveira EXG, Travassos C, Carvalho MS. Acesso à internação hospitalar em municípios brasileiros em 2000: territórios do Sistema
Único de Saúde. Cad Saude Publica. 2004; 20(2):298-309.

24. Lucchese PTR. Equidade na gestão descentralizada do SUS: desafios para a redução da desigualdade em saúde. Cienc Saude Coletiva. 2003;8(2):439-48

25. Matos CA, Pompeu JC. Onde estão os contratos? Análise da relação entre os prestadores privados de serviços de saúde e o SUS. Cienc Saude Coletiva. 2003;8(2):629-43.

26. Escorel S, Delgado MM. Perfil dos conselhos estaduais de saúde: singularidades e similaridades no controle social. Divulg Saúde Debate. 2008;43:62-78

27. Gerschman S. Conselhos Municipais de Saúde: atuação e representação das comunidades populares. Cad Saúde Publica. 2004; 20(6):1670-81.

28. Kuschnir R. A Construção da regionalização: nota Técnica sobre o pacto pela saúde. Versão preliminar. Rio de Janeiro: ENSP; 2007.

29. Azevedo S, Anastácia F. Governança, "accountability" e responsividade. Rev Econ Polit 2002;1(22):79-97.

30. Reis FW. Governabilidade, instituições e partidos. Novos Estudos CEBRAP. 1995;41:40-59.

31. Brasil, Ministério da Saude. Lei 8 080/90. Disponível em: www.planalto.gov.br/ccivil_03/ Leis/L8080.htm. Acessado em abril de 2009.

32. Brasil, Ministério da Saúde. Lei 8 142/90. Disponível em: www.planalto.gov.br/ccivil_03/ Leis/L8142.htm. Acessado em abril de 2009.
33. Fleury S. Universal, dual or plural? Health care models and issues in Latin America. Em: Molina CG, Arco JN, orgs. Health services in Latin America and Asia. Washington D.C: Interamerican Development Bank; 2001. Pp 3-36.

34. Monteiro MG, Fleury S. Democracia deliberativa nas gestões municipais de saúde: um olhar sobre a importância dos conselhos municipais de saúde nas gestões. Rev Saude Debate. 2006;30(73/74):219-33.

35. Labra, ME. Política nacional de participação na saúde; entre a utopia democrática do controle social e a práxis predatória do clientelismo empresarial. Em: Fleury S, Lobato LVC, orgs. Participação, democracia e saúde. Rio de Janeiro: Editora Cebes; 2009. Pp. 176-203.

36. Escorel S, Moreira MR. Desafios da participação social em saúde na nova agenda da reforma sanitária: democracia deliberativa e efetividade. Em: Fleury S, Lobato LVC, orgs. Participação, democracia e saúde. Rio de Janeiro: Editora Cebes; 2009. Pp. 228-247.

37. Côrtes SMV. Conselhos e conferências de saúde: papel institucional e mudança nas relações entre Estado e sociedade. Em: Fleury S, Lobato LVC, orgs. Participação, democracia e saúde. Rio de Janeiro: Editora Cebes; 2009. Pp. 102-28.

Manuscrito recebido em 15 de dezembro de 2009. Aceito em versão revisada em 24 de julho de 2010.

ABSTRACT Objective. To analyze the changes in local health care governance resulting from the decentralization process associated with the Unified Health System (SUS) in Brazil between 1996 and 2006.

\section{Local governance in the decentralized health care system in Brazil}

Methods. A questionnaire was answered in 1996 and again in 2006 by all city officials involved in health care management in Brazil. Information was collected on the innovative characteristics of administrative practices in terms of three dimensions: social, management, and care. The present article analyzes the results relating to the social dimension (relationship between municipal officials and the various community actors) according to four attributes: preparing the budget (degree of influence of various actors), establishing priorities, accountability, and flow of information to the community. Results. The influence of municipal secretaries of health and health councils on budget preparation has increased, with a decrease of local politician influence. In prioritizing health issues, local politicians and spontaneous demands have also become less influential, with strengthening of the influence of technical opinions and proposals by health councils and conferences. Public disclosure of results has become institutionalized as a result of the diversification of stakeholders (especially municipal secretaries and health councils) and of the methods available for disclosure, even though balance sheets are still the most common type of information disclosed (which imply technical knowledge for interpretation of results). Finally, the information conveyed to the community still mainly refers to health actions and campaigns and functioning of health services, even though a larger amount of innovative information is being communicated. This was observed in all regions and in cities of all sizes, with a more progressive trend in the South of Brazil.

Conclusions. The relationship between government and society has changed toward a more democratic standard of local governance, despite the maintenance of centralized government decision-making practices. The process of decentralization still faces important obstacles to the establishment of a more participative model, with enhanced social control, accountability and interaction between government and society.

Key words Unified Health System; decentralization; local government; health policy; Brazil. 